\title{
Group therapy in the treatment of childhood sexual abuse
}

\author{
Janet Boakes
}

\begin{abstract}
Group psychotherapy for adults reporting childhood sexual cbuse is a well recognised form of treatment but little attention has been given to the possible adverse effects. This paper reports on three patients seen within a NHS trust department of psychothercpy who had taken part in an incest 'survivor group'. They described individual satisfaction with their improvement but appeared, when viewed extemally, to have deteriorated.
\end{abstract}

Group psychotherapy is frequently used in the treatment of adults who give a history of childhood sexual abuse. Ganzarin \& Buchele (1986) advocate a peer group as offering members the opportunity to explore the meaning of their experience with others who have similarly suffered. The healing power of catharsis has long been recognised and the group offers members an opportunity to address emotional difficulties derived from incest and so catch-up on missed emotional growth. Herman (1992) favours group treatment because it allows people to break through the secrecy which surrounds sexual abuse. Telling others is the first step towards recovery. Re-telling the incident brings a feeling of belonging and helps to lessen the sense of isolation experienced by the abused. Participants commonly report that their symptoms initially worsen but that simultaneously they experience a sense of euphoria at being recognised and understood for the first time. Guilt and shame observed are seen to be irrational and group members commonly absolve the guilt of others before eventually coming to apply the same tolerance and forgiveness to themselves. An advantage for the therapist is that transferences within the group are less intense than in individual treatment and consequently easier to manage (Ganzarin \& Buchele, 1986).

It is widely believed that new memories will emerge during group psychotherapy and will further the work of 'healing' from sexual abuse. Strong group cohesion develops quickly and bonding provides a stimulus to the recovery of painful memories, as each vivid narrative provokes other participants to recollect similar stories. However, these same attributes of group therapy have given rise to concerns that 'survivor groups' may have adverse consequences as well as beneficial effects (Ofshe \& Watters, 1994; Pope \& Hudson, 1995).

Herman \& Schatzow (1987) mixed patients who had never forgotten abuse with patients who had no memories of this kind but where either the patient or the clinician believed that forgotten sexual abuse might lie at the root of psychological symptoms. During the group many patients appeared to recover new memories of previously forgotten abuse. Herman \& Schatzow viewed this as evidence for the repression of sexual abuse. However, their findings have been criticised (Ofshe and Watters, 1994; Pendergrast, 1995; Pope \& Hudson, 1995) for failing to take account of infantile amnesia, unlikely or improbable scenarios, and the possibility of suggestion and contagion among group members. These authors argue that many of the group members came to 'remember' events to fit their own and the therapist's expectations of memory recovery and that peer group suggestion had played a key part.

In the present climate of uncertainty about recovered memory and false memory, any empirical evidence is potentially useful. I describe three cases presenting to a NHS trust psychotherapy department following attendance at a 'survivor group', who reported individual satisfaction but clinically appeared to be worse.

During the period October 1995 to March 1996 three adult patients were referred for treatment of sexual abuse. Each had been a member of an incest 'survivor group'. Two of these groups had been run within the NHS and the third was a voluntary group and nothing is known of the training or credentials of the group leader.

\section{Case histories}

\section{Case 1}

A., a 26-year-old from a rural background, had never forgotten sexual abuse by both her uncle and grandfather, which, however, she strove to push to the back of her mind. After counselling she was referred to a group for survtvors of sexual abuse. She went on to remember previously unknown or forgotten abuse. including abuse by her father, until then the one man 
in her life she believed had not abused her. She started to have symptoms of post-traumatic stress disorder (PTSD) - flashbacks, intrusive thoughts. panic attacks and nightmares.

She found the group comforting because there were other people who had been through similar experiences, with whom she formed a bond, and she left feeling both angrier and much stronger. However instead of pushing her memories to the back of her mind she now could not forget her childhood abuse. She continued to have symptoms, was unable to work, began to drink heavily and used cannabis to sleep. Before joining the group her memorles had been clear but following the group they were muddled and she was no longer sure what had happened to her. She sought further help for depression and worries about the effect of her moodiness and temper on her seven-year-old daughter. She was referred to us for further work on her sexual abuse in order to free herself from its influence.

She was markedly ambivalent about treatment failing two appointments and becoming resentful when asked about her past experiences. Following assessment she realised the extent to which she was ruminating upon her past and ignoring current difficulties. She refused further exploratory psychotherapy and shyly volunteered that she would like to learn to read and write. Now settled with a psychiatrist and a care plan which includes parenting skills, plans for further education, and emphasis on her strengths rather than her past wrongs, she is doing well.

\section{Case 2}

B., a 38-year-old man, first presented in 1993 with depression and excessive drinking. He gave a history of masturbation by a family member from the age of nine to 14 and a forced incestuous relationship with his older sister at 15. He was offered treatment but failed to take it up at the time.

He presented again in 1996 following his father's death six months previously. Within hours of the death he disclosed his sexual abuse to the family. He recalls that he was 'not his normal restrained self at the time. He went on a spending spree after his mother had promised to give him money from his father's estate. In the event the money was not forthcoming but by then he had run up heavy debts and he became depressed. He was off work for three months and during this time be became obsessed with his past abuse.

He joined a self-help group for survivors, began to read 'survivor' literature, and to keep a journa recording his thoughts and memories. Suddenly he was seeing connections between events and everything appeared to make sense. While in the group he had occasional panic attacks and nightmares. He also described hypnogogic hallucinations of the abuser, and one episode of sleep paralysis. He came to view previously disregarded events as instances of sexual abuse and recovered new memories of abuse by two catholic priests whom he reported to the Church.

On leaving the group he was relieved and elated to have met people with similar histories and could think and talk of nothing but sexual abuse. His family thought he was unstable and needed help, and his girlfriend left him because of his preoccupation. He wanted to help others as he felt he had been helped and arranged a meeting for abuse victims which attracted media attention and led to his appearing on national radio and TV. He reported his abuser to the police and was angered when they took no action because of the lapse of time since the reported events.

He sought further treatment for his sexual abuse. His current problems of failed relationships, job failure, low self-esteem, and alcoholism were effectively concealed by his history. He had established an identity as a 'survivor' from which he derived increased self-esteem, while the hope of helping others gave meaning to his life. However, his preoccupation had a detached quality to it, akin to belle indifference and he continued to have occasional nightmares and panic attacks.

He appeared to have decompensated following his father's death. becoming obsessed with sexual abuse but failing to mourn. He had destroyed his relationship with his girlfriend and his surviving family members, all of whom thought he showed signs of mental instability.

\section{Case 3}

C., aged 27, joined a survivor group following abuse in early adolescence. She had never forgotten her history but it did not occur to her to call it abuse until an article in a magazine made her view her past in a different light and she sought counselling. During the group she developed symptoms of PTSD for the first time and went on to recover additional memories extending back to the age of three. Her account of events was vague and confused and it was not clear which were core memories and which were later elaborations. (The memory at the age of three lies within the period of infantile amnesia.) Like the others she left the group stronger and angrier. obsessed with abuse and revenge. However, she was still experiencing panic attacks and nightmares six months later and her problems with mood, poor selfcontrol and relationships were unchanged. She sought further treatment for her sexual abuse but did not take up the offer.

\section{Comment}

Patient satisfaction and clinical effectiveness do not always coincide. The subjects reported feeling better following group treatment. They were angrier, felt stronger and generally were satisfied with the experience. They valued sharing their experiences with others similarly affected. Group factors (Yalom, 1975) of cohesiveness, universality, altruism and simple catharsis appeared to be helpful, as did mirroring (Foulkes, 1948) of problems by other group members. However, each of the three appeared objectively to be more disturbed. They reported new symptoms, adverse effects on relationships and preoccupation with abuse. Instead of being 
freed from the past, they were obsessed by it and adjustment to daily living had suffered.

They exhibited features of PTSD which were directly related to the apparent recollection of childhood abuse rather than to the event. Far from being cathartic, rehearsal of past trauma led to increased arousal and the development of symptoms. Although some (Hall, 1992; Herman, 1992), consider that worsening of symptoms is a necessary prelude to recovery, these patients did not improve with time and their original complaints remained unchanged.

All three reported the emergence of what seemed to be new memories. As these were progressively elaborated, it became hard to disentangle memories of the core, never forgotten abuse, from more recent and less certain memories. Although the past seemed to give meaning to their difficulties and hence contributed to their feeling better, some of the connections made were of doubtful validity. One was left confused about her own mind and lost the only good parental figure from her childhood. One established a new identify as a 'survivor' with apparent secondary gain.

\section{Conclusions and recommendations}

Clinicians should be cautious when a patient seeks treatment for past sexual abuse rather than for current problems. There appears to be a tendency to 'treat' for sexual abuse all those who give such a history, regardless of its current relevance. Although some people undoubtedly need treatment for the consequences of abuse it is less clear that sexual abuse per se requires treatment. No reliable information exists about which patients should be encouraged to abreact their abusive experience, and which should be encouraged to put it behind them and turn their attention elsewhere. (The first example clearly stated that she did not want to dwell on the past, and settled well into a different regime.)

Individuals seeking treatment for past sexual abuse should be assessed carefully before automatic assignment to a therapy group. Clinicians should ask themselves how the past abuse is manifest in current problems. If there is no obvious link, it may well be a chance connection, and a focus on the abuse may ignore other eminently treatable conditions (as in the second case where the death of the father was overlooked in favour of sexual abuse).

Not enough is known about the factors which influence the outcome in groups. Further research is needed into delayed PTSD and any possible iatrogenic component. Research is also needed into the qualities of 'recovered memories' in order to distinguish them from the effects of suggestion.

Clearly a sample of three is too small from which to draw any firm conclusions. No attempt to check the previous history of the patients was made. However, it appears from these cases that group therapy for adults who have been sexually abused as children carries a risk of causing a patient to develop disabling symptoms for the first time. This may be at variance with the patient's subjective experience of feeling greatly helped by the group. Some people may be led to remember additional events of questionable veridity.

\section{References}

Foulkes, S. H. (1948) Introduction to Group Analytic Psychotherapy. Reprinted in 1983. London: Maresfield Reprints.

GANZARIN, R. \& BUCHELE, R. (1986) Countertransference when incest is the problem. International Joumal of Group Psychotherapy. 38, 549-566.

HALL, Z. (1992) Group therapy for women survivors of childhood sexual abuse. Group Analysts, 26, 463-475.

Herman, J. L. (1992) Trauma and Recovery. New York: Basic Books.

- \& SCHATzOW, E. (1987) Recovery and verification of memories of childhood sexual trauma. Psychoanalytic Psychology. 4, 1-14.

Orshe, R. J. \& WATters, E. M. (1994) Making Monsters: False Memorles. Psychotherapy, and Sexual Hysteria. pp. 305-314. New York: Scribner's Sons.

Pendergrast, M. (1995) Victims of Memory: Incest Accusations and Shattered Lives. Hinesberg. VT: Upper Access Books

POPE, H. G. \& HUDSON, J. J. (1995) Can memorles of childhood sexual abuse be repressed? Psychological Medicine, 28, 121-126.

YALOM. I. D. (1975) The Theory and Practice of Group Psychotherapy. New York: Basic Books.

Janet Boakes, Consultant Psychotherapist, Pathfinder NHS Trust, 1st Floor, Clare House, St George's Hospital, Blackshaw Road, London SW17 OQT 